九州大学学術情報リポジトリ

Kyushu University Institutional Repository

Effect of Mevalonic Acid on Lactate Fermentation Using Pediococcus sp. ISK-1

Herawati, Etmy

Laboratory of Microbial Technology, Faculty of Agriculture, Kyushu University

Ishizaki, Ayaaki

Laboratory of Microbial Technology, Faculty of Agriculture, Kyushu University

https://doi.org/10.5109/24134

出版情報：九州大学大学院農学研究院紀要. 41 (1/2)，pp.91-104，1996-11. Kyushu University バージョン：

権利関係 : 


\title{
Effect of Mevalonic Acid on Lactate Fermentation Using Pediococcus sp. ISK-1
}

\author{
Etmy Herawati and Ayaaki Ishizaki \\ Laboratory of Microbial Technology, Faculty of Agriculture, \\ Kyushu University, Fukuoka 812-81, Japan \\ (Received July 31, 1996)
}

\begin{abstract}
The growth of a newly isolated strain of Pediococcus sp., designated ISK-1 was very slow and the concentration of cells in the medium remained low. Fermentation with an initial $30 \mathrm{~g} / \mathrm{l}$ glucose required about $60 \mathrm{~h}$. In order to stimulate fermentation, we attempted to optimize of the medium by flask culture and jar fermentation tests. Mevalonic acid and mieki (soy bean hydrolyzate) stimulated fermentation and increased the rate of formation of $x$-lactate. Kinetic analysis of the fermentation revealed that mevalonic acid increased markedly the specific glucose consumption rate and the specific lactate production rate. Mieki and mevalonic acid had a synergistic effect, but the effect of mevalonic acid was different from that of mieki.
\end{abstract}

\section{INTRODUCTION}

Pediococcus spp. are present as natural flora in various fermented foods and are used as commercial starter cultures in the production of fermented sausages (Amy and Hoover, 1988), sauerkraut and pickles (Blickstad and Goran, 1981). Many types of fermented food are produced from plant sources throughout the world and they can be divided into several groups. Pediococci are found as very common microorganisms in various foods, but, the studies of this genus have been limited. Pediococcus sp. ISK-1 was isolated in our laboratory from nukadoko which is the name given to the rice-bran packed fermentation bed used for preparation of home-made Japanese traditional pickled vegetables. Strain ISK-1 has very interesting characteristics; it produces a novel bacteriocin; it has strong arginine-hydrolyzing activity; it generates oxygen efficiently from hydrogen peroxide. However, its growth in nutrient medium is very poor. In complete medium with glucose (CMG), which consisted of yeast extract and polypeptone as nutrients, about $60 \mathrm{~h}$ were required for consumption of $30 \mathrm{~g} / \mathrm{l}$ glucose at a cell density of approximate $4.5 \mathrm{~g} / \mathrm{l}$. For reasonable growth and the production of lactate, it $i s$ important to improve the growth medium for this microorganism. It seem that the genus Pediococcus has rather complex nutritional requirements, and that amino acids, vitamins and special growth promoters, such as mevalonic acid, are required for its rapid growth.

The effects of mevalonic acid on the growth of lactic acid microorganisms were first reported by Kitahara et al., (1957). Lactobacillus homohiochi, which was isolated from sake, failed to growth in MRS broth (Sneath et al., 1986). However in Rogosa SL broth (Sneath et $a l .$, 1986) supplemented with DL-mevalonic acid $(30 \mathrm{~g} / \mathrm{l})$ and ethanol $(40 \mathrm{~g} / \mathrm{l})$ copious growth is obtained after a marked lag phase of 4-7 days. Thus, it seems that mevalonic acid is essential or highly stimulator-y and that ethanol is promotive for growth of $L$. homohiochi. However, no reports on the effects of mevalonic acid on the genus Pediococcus are available. We describe here the stimulatory effects of mevalonic acids as 
well as of amino acids, on the growth of Pediococcus sp. ISK-1, a new strain isolated from nukadoko. We also describe our investigations of the fermentation kinetics of this strain in improved media during jar culture.

\section{MATERIALS AND METHODS}

\section{Microorganism}

The microorganism used in this study was Pediococcus sp. ISK-1 that had been stored in a deep freezer $\left(-80^{\circ} \mathrm{C}\right)$. The microorganisms were grown at $37^{\circ} \mathrm{C}$ for $18 \mathrm{~h}$ in thioglycolate (TGC) medium (Difco Laboratories, Detroit, MI) that had been autoclaved at $121^{\circ} \mathrm{C}$ for $15 \mathrm{~min}$. for rejuvenate.

\section{Medium}

A $100-\mathrm{m} l$ aliquot of CMG consisting of $5.0 \mathrm{~g}$ yeast extract, $5.0 \mathrm{~g}$ polypeptone, $5.0 \mathrm{~g}$ $\mathrm{NaCl}$ and $10.0 \mathrm{~g}$ glucose in 1 liter of deionized waters was used for preculture. A 400-ml aliquot of CMG prepared with only $3.0 \mathrm{~g} / \mathrm{t}$ yeast extract and with $30.0 \mathrm{~g} / \mathrm{l}$ glucose was used for jar cultures. The $\mathrm{pH}$ of the medium was adjusted to 7.0 with $1 \mathrm{~N} \mathrm{KOH}$ and $1 \mathrm{~N} \mathrm{HCl}$ and the medium was sterilized at $121{ }^{\circ} \mathrm{C}$ for $15 \mathrm{~min}$. An amino acid mixture was prepared such that the amino acid composition of the medium would be equivalent to medium that contained $5.0 \%$ mieki. Thus, $130 \mathrm{mg}$ of L-alanine, $250 \mathrm{mg}$ of L-arginine, $500 \mathrm{mg}$ of Laspartic acid, $12 \mathrm{mg}$ of L-cysteine, $850 \mathrm{mg}$ of L-glutamic acid, $220 \mathrm{mg}$ of glycine, $110 \mathrm{mg}$ of L-histidine, $180 \mathrm{mg}$ of L-isoleucine, $200 \mathrm{mg}$ of L-leucine, $300 \mathrm{mg}$ of L-lysine, $25 \mathrm{mg}$ of Lmethionine, $200 \mathrm{mg}$ of L-phenylalanine, $200 \mathrm{mg}$ of L-serine, $170 \mathrm{mg}$ of L-threonine, $60 \mathrm{mg}$ of L-tyrosine, and $235 \mathrm{mg}$ of L-valine were dissolved in $50 \mathrm{ml}$ of deionized water. The amino acid solution was then added to $50 \mathrm{ml}$ of $2 \times \mathrm{CMG}$ and the solution was brought to $100 \mathrm{ml}$. Synthetic medium was prepared by the method described by Uchimura and Okada (1992). The medium consisted of $20 \mathrm{~g}$ of glucose, $10 \mathrm{~g}$ of potassium acetate, $3 \mathrm{~g}$ of $\mathrm{NH}_{4} \mathrm{Cl}, 500 \mathrm{mg}$ of $\mathrm{K}_{2} \mathrm{HPO}_{4}, 500 \mathrm{mg}$ of $\mathrm{KH}_{2} \mathrm{PO}_{4}, 200 \mathrm{mg}$ of $\mathrm{MgSO}_{4} \cdot 7 \mathrm{H}_{2} \mathrm{O}, 10 \mathrm{mg}$ of $\mathrm{MnSO}_{4}$ $4 \mathrm{H}_{2} \mathrm{O}, 10 \mathrm{mg}$ of $\mathrm{FeSO}_{4} 7 \mathrm{H}_{2} \mathrm{O}, 10 \mathrm{mg}$ of $\mathrm{NaCl}, 1 \mathrm{mg}$ of thiamine $\mathrm{HCl}, 1 \mathrm{mg}$ of riboflavin, $1 \mathrm{mg}$ of niacin, $1 \mathrm{mg}$ of Ca-pantothenate, $1 \mathrm{mg}$ of pyridoxine $\mathrm{HCl}, 1 \mathrm{mg}$ of pyridoxal $\mathrm{HCl}, 200 \mu \mathrm{g}$ of p-amino benzoic acid, $10 \mu \mathrm{g}$ of folic acid, $10 \mu \mathrm{g}$ of biotin, $200 \mathrm{mg}$ of L-alanine, $200 \mathrm{mg}$ of L-arginine $\mathrm{HCl}, 200 \mathrm{mg}$ of L-aspartic acid, $100 \mathrm{mg}$ of L-cystein $\mathrm{HCl}, 500 \mathrm{mg}$ of L-glutamic acid (sodium salt), $100 \mathrm{mg}$ of glycine, $100 \mathrm{mg}$ of L-histidine $\mathrm{HCl}, 100 \mathrm{mg}$ of L-isoleucine, $100 \mathrm{mg}$ of L-leucine, $200 \mathrm{mg}$ of L-lysine $\mathrm{HCl}, 100 \mathrm{mg}$ of L-methionine, $100 \mathrm{mg}$ of Lphenylalanine, $100 \mathrm{mg}$ of L-proline, $50 \mathrm{mg}$ of L-serine, $100 \mathrm{mg}$ of L-threonine, $50 \mathrm{mg}$ of Ltryptophane, $100 \mathrm{mg}$ of L-tyrosine, $100 \mathrm{mg}$ of L-valine, $10 \mathrm{mg}$ of adenine $\mathrm{H}_{2} \mathrm{SO}_{4}, 10 \mathrm{mg}$ of guanine $\mathrm{HCl}, 10 \mathrm{mg}$ of uracil, and $10 \mathrm{mg}$ of xanthine per liter of deionized water. The $\mathrm{pH}$ was adjusted to 6.8 with $1 \mathrm{~N} \mathrm{NaOH}$ and $1 \mathrm{~N} \mathrm{HCl}$ and the medium was autoclaved at $110^{\circ} \mathrm{C}$ for $10 \mathrm{~min}$. All amino acids (medical grade) and mieki (soybean protein hydrolysate) were a gift from Ajinomoto Co. Ltd. (Tokyo, Japan).

$( \pm)$ Mevalonic lactone (97\%) was purchased from Aldrich Chemical. Co., (Milw, WI). 


\section{Flask culture for optimization of the medium}

Flask culture was used for the screening of effective components of the medium. Preculture was carried out in $100 \mathrm{ml}$ of CMG in an Erlenmeyer flask. After inoculation with $10 \mathrm{ml}$ of subculture, the flask was incubated in a water bath at $37^{\circ} \mathrm{C}$ for $6 \mathrm{~h}$ with agitation of $100 \mathrm{rpm}$. The $\mathrm{pH}$ of the culture broth was maintained at an almost constant value by addition of $2.0 \%(\mathrm{w} / \mathrm{v}) \mathrm{CaCO}_{3}$ after the initial stage of the culture. Flasks were shaken at 100 oscilations per min. with a stroke of $25 \mathrm{~mm}$ in a water bath whose temperature was maintained at $37^{\circ} \mathrm{C}$. The "one at a time" method was used for screening (Chen et al., 1981; Chynier et al., 1983; Bowman and Geiger, 1984; Zertuche and Zall, 1985; Houng et al., 1989; Silveira et al., 1991). In this method, one component at different concentrations is tested without any change in the other constituents of the basal medium. The effects of the target component on various kinetic parameters of fermentation were then evaluated. The optimum medium was prepared with the optimum levels of the selected ingredients.

\section{Jar culture experiment}

Twenty $\mathrm{ml}$ of the preculture were inoculated into a $1-\mathrm{Z}$ jar fermentor with a working volume of $400 \mathrm{ml}$. The culture was incubated at $37^{\circ} \mathrm{C}$ with agitation of $400 \mathrm{rpm}$ without gas flow. The $\mathrm{pH}$ was controlled at 6.0 by feeding $2 \mathrm{~N} \mathrm{NaOH}$.

\section{Analysis}

The cell density of the culture was determined from the optical absorbance at 562 $\mathrm{nm}$, measured with a spectrophotometer (Uvidec 320; JAS Co., Tokyo, Japan). The absorbance was then converted to DCW (dry cell weight) by reference to a predetermined standard curve. Glucose and L-lactate were quantitated by enzymatic analyzers (models 23A and 23L respectively; Yellow Spring International Co. Ltd., Ohio, USA). DL-lactate was quantitated by HPLC (model 638-30; Hitachi, Tokyo, Japan with BIO-RAD an HPX-87H column) and an mobile phase of $0.005 \mathrm{~N} \mathrm{H}_{2} \mathrm{SO}_{4}$. Optical absorbance was monitored with a UV-VIS detector (model SPD-10 A; Shimadzu Co., Kyoto, Japan). The DL-lactate concentration in the culture broth in which DL-lactate formed a sediment as calcium compound was determined from the following formula :

$$
\mathrm{Y}=1.812 \mathrm{X}
$$

where $\mathrm{Y}$ is the true concentration of L-lactate $(\mathrm{g} / \mathrm{l})$ in a culture medium that contains $2.0 \%$ $\mathrm{CaCO}_{3}$ at concentrations of L-lactate from 0 to $5.74 \mathrm{~g} / \mathrm{Z}$ and $\mathrm{X}$ is the concentration of $\mathrm{L}$ lactate $(\mathrm{g} / \mathrm{l})$ measured by an enzyme sensor at concentrations of L-lactate from 0 to 10.4 $\mathrm{g} / l$.

\section{RESULTS}

\section{Growth of Pediococcus Sp. ISK-1 in CMG}

In a standard experiment, strain ISK-1 was cultured in a jar fermentor in CMG (30 g/l glucose) to serve as the control culture. Figure 1 shows the time course of fermentation. Culture conditions for the jar culture were a temperature of $37^{\circ} \mathrm{C}, \mathrm{pH}$ of 6.0 , and gentle agitation without gas flow, as described in Materials and Methods. Samples were 


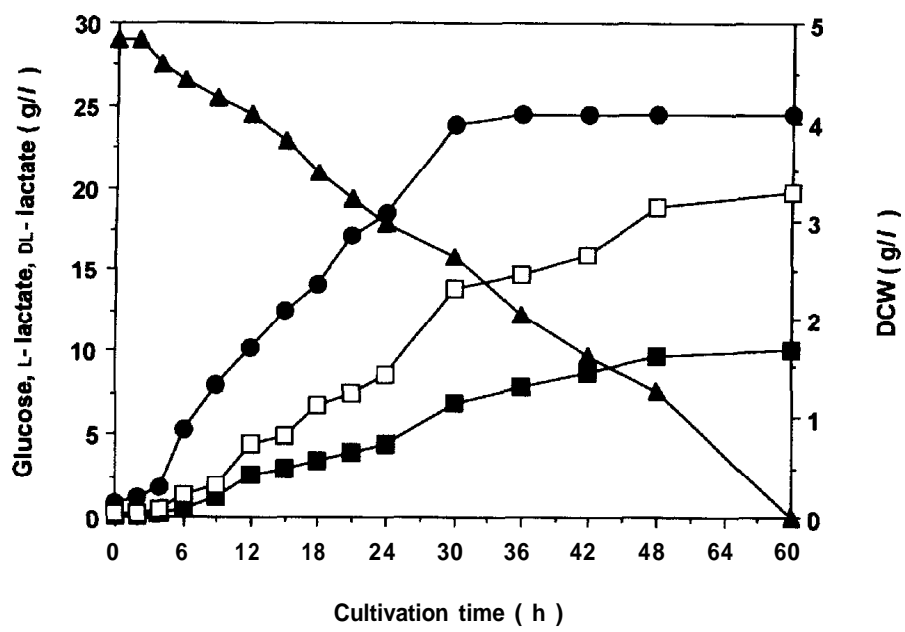

Fig. 1. Time course for jar culture of Pediococcus sp. ISK-1 grown in CMG. DCW ( ), glucose consumption (A), L-lactate production ( $\boldsymbol{\square})$, DLlactate production $(\square)$.

withdrawn at approximately two or three hour intervals during the lag phase, at six hour intervals during the logarithmic phase and twelve hour intervals during the stationary phase and analized immediately. The concentration of cells reached its a maximum value of $4.08 \mathrm{~g} / l$ at stationary phase, when nearly $50 \%$ of the initial glucose had been consumed at $36 \mathrm{~h}$ and the concentration of L-lactate was $7.80 \mathrm{~g} / \mathrm{l}(14.75 \mathrm{~g} / \mathrm{l}$ of DL-lactate). Fermentation was completed a within $60 \mathrm{~h}$ when $10.1 \mathrm{~g} / \mathrm{l}$ L-lactate and $19.7 \mathrm{~g} / \mathrm{E}$ DL-lactate had accumulated. Although CMG contains excellent sources of nutrients, such as yeast extract and polypeptone, and with glucose is present as a carbon source, the growth of strain ISK-1 was very slow and the rate of accumulation of lactic acid was unsatisfactory. When sucrose was used in place of glucose as a carbon source, the fermentation rate increased slightly (data not shown). Therefore, in order to study the characteristics of this strain, it was necessary to improve the medium and culture conditions to obtain higher cell densities and concentrations during relatively short times.

\section{Effect of Tween 80, mieki and amino acid mixture}

Tween 80 has often been used in the medium for growth of anaerobic microorganisms, such as MRS medium and Bifidobacterium medium (Oiki et al., 1996). We tested the effects of Tween 80 on the growth and fermentation of strain ISK-1 in flask culture. Then we studied the effects of amino acids using mieki.Mieki which is soybean protein hydrolysate provided by Ajinomoto Co, Ltd, Tokyo. The total nitrogen content of mieki was equivalent to $3.5 \mathrm{~g} / l$.

The basal medium used in the experiments in flask culture was CMG containing $2.0 \%$ $\mathrm{CaCO}_{3}$. As shown in Figure 2, Tween 80 had the opposite effect on both growth and 


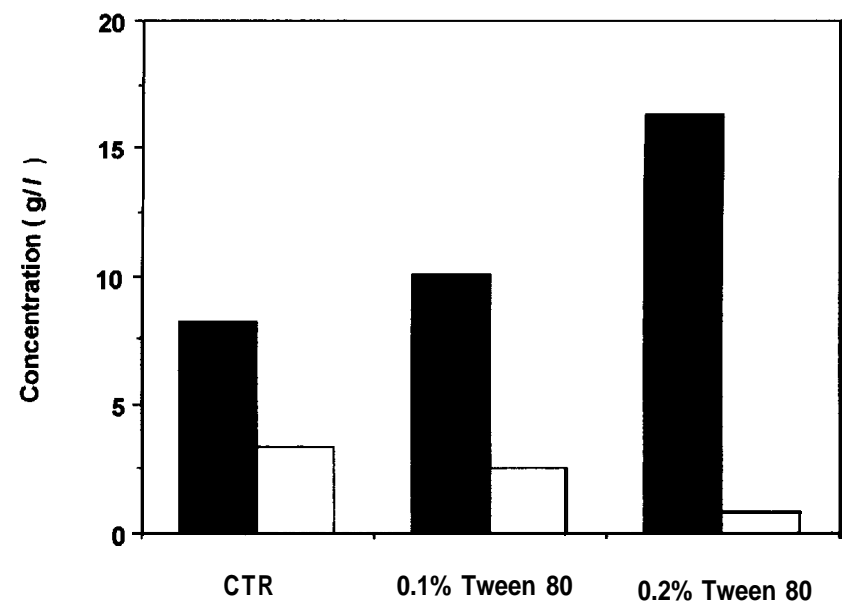

Fig. 2. Effect of Tween 80 on fermentation by Pediococcus sp. ISK-1 in flask culture at $24 \mathrm{~h}$. Glucose consumption ( $\square$ ), L-lactate production ( $\square$ ).

fermentation. The residual glucose and L-lactate concentrations in the CMG used as control medium (CTR) were 8.16 and $3.33 \mathrm{~g} / l$ respectively. Supplementation of $0.1 \%$ and $0.2 \%$ Tween 80 inhibited the consumption of glucose and the production of L-lactate. The residual glucose and the L-lactate production in CMG with $0.1 \%$ Tween 80 and $0.2 \%$ Tween 80 were 10.06 and 2.49 , and 16.33 and $0.83 \mathrm{~g} / \mathrm{Z}$ respectively. Next we postulated that strain ISK-1 might have very complex requirements for ammo acid. The amino acid composition of mieki, according to the supplier, is $5.4 \mathrm{~g}$ of L-alanine, $10.0 \mathrm{~g}$ of L-arginine, $20.5 \mathrm{~g}$ of L-aspartic acid, $0.5 \mathrm{~g}$ of L-cysteine, $34.5 \mathrm{~g}$ of L-glutamic acid, $8.8 \mathrm{~g}$ of glycine, 4.4 $\mathrm{g}$ of L-histidine, $7.4 \mathrm{~g}$ of L-isoleucine, $8.0 \mathrm{~g}$ of L-leucine, $12.2 \mathrm{~g}$ of L-lysine, $0.5 \mathrm{~g}$ of L-methionine, $8.0 \mathrm{~g}$ of L-phenylalanine, $8.0 \mathrm{~g}$ of L-serine, $7.0 \mathrm{~g}$ of L-threonine, $2.5 \mathrm{~g}$ of L-tyrosine, 9.5 $\mathrm{g}$ of $\mathrm{L}$-valine per liter. We examined the effects of concentrations of mieki from $1.0 \%$ to $5.0 \%$. Figure 3 shows that mieki stimulated fermentation and product formation. As compared with the control culture, mieki at $3.0 \%$ stimulated glucose consumption and lactate formation. At $5.0 \%$ mieki, the initial glucose $(30 \mathrm{~g} / l)$ was completely consumed within $24 \mathrm{~h}$ and almost $50 \%$ of the glucose was converted to L-lactate. Further studies were carried out to investigate whether the effect of mieki was due to amino acids or to growth promoters other than amino acids. A flask culture with medium plus an amino acid mixture with concentrations of ammo acids that were almost the same as those in $5.0 \%$ mieki was carried out. Flask culture tests using synthetic medium consisted of minerals, vitamins and amino acids were also carried out. Results are shown in Figure 4. CMG with mieki was markedly better than CMG with ammo acid mixture. Amino acid concentrations in the synthetic medium were almost the same as those in medium supplemented with mieki or with the ammo acid mixture. However, the fermentation 


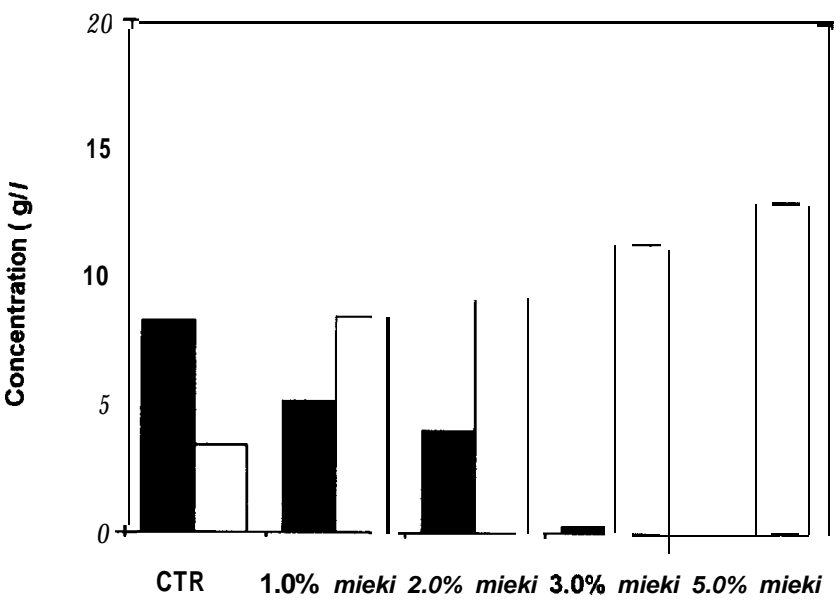

Fig. 3. Effect of mieki on fermentation by Pediococcus sp. ISK-1 in flask culture at $24 \mathrm{~h}$.

Symbols are the same as in Fig. 2.

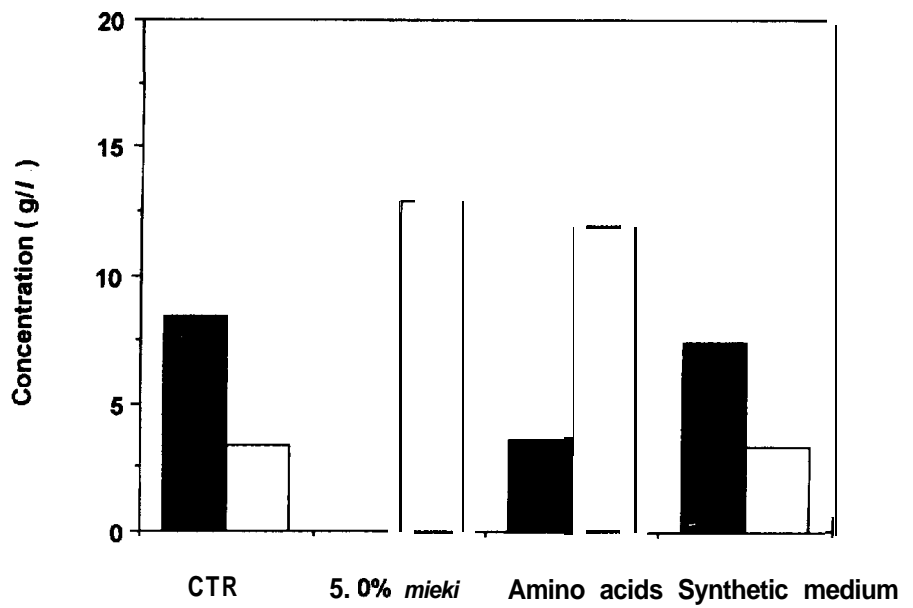

Fig. 4. Effect of mieki, amino acids and synthetic medium on fermentation by Pediococcus sp. ISK-1 in flask culture at $24 \mathrm{~h}$.

Symbols are the same as in Fig. 2. 
rate and product formation in the synthetic medium were very much lower than those in CMG with mieki and CMG with the amino acid mixture. These observations suggest that natural nutrients, such as yeast extract and polypeptone, contain excellent growth promoters that cannot be provided by the synthetic medium. Moreover, mieki might contain special growth promoters for strain ISK-1 in addition to amino acids. It is known that mieki contains large amounts of levulinic acid. However, this acid did not affect the growth of strain ISK-1 (data not shown). To identify the growth promoter of strain ISK-1, we tested the effects of mevalonic acid.

\section{Effects of mevalonic acid}

In order to obtain a better understanding of the growth and lactic acid production by ISK-1 in complete medium, we carried out flask cultures test with added mevalonic acid. Using the same basal medium as in the flask cultures described in the previous section, we investigated the effects of mevalonic acid at concentrations from $1 \mathrm{ppb}$ to $100 \mathrm{ppm}$ on the growth and lactate production by ISK-1. The results are shown in Figure 5. As shown in this Figure 5, the effect of mevalonic acid was remarkable observed. At $100 \mathrm{ppm}$ mevalonic acid, substrate consumption and lactate formation were stimulated and results of fermentation after a $24 \mathrm{~h}$ culture were almost the same as those obtained with CMG plus $5.0 \%$ mieki.

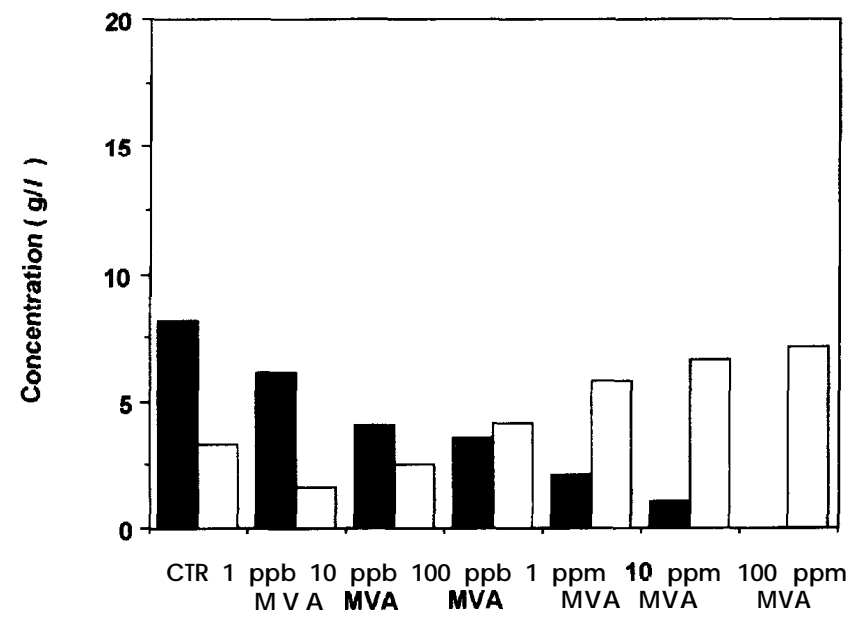

Fig. 5. Effect of mevalonic acid on fermentation by Pediococcus sp. ISK-1 in flask culture at $\mathbf{2 4} \mathrm{h}$.

Symbols are the same as in Fig. 2. 


\section{Optimization of jar culture}

To confirm the results obtained in the flask culture tests, we performed a jar fermentation experiment at a regulated pH. CMG with 5.0\% mieki, CMG with $10 \mathrm{ppm}$ mevalonic acid and CMG with 5.0\% mieki and $10 \mathrm{ppm}$ mevalonic acid were tested. The results are shown in Figure 6, 7 and 8. Figure 6 shows that in CMG with 5.0\% mieki, the

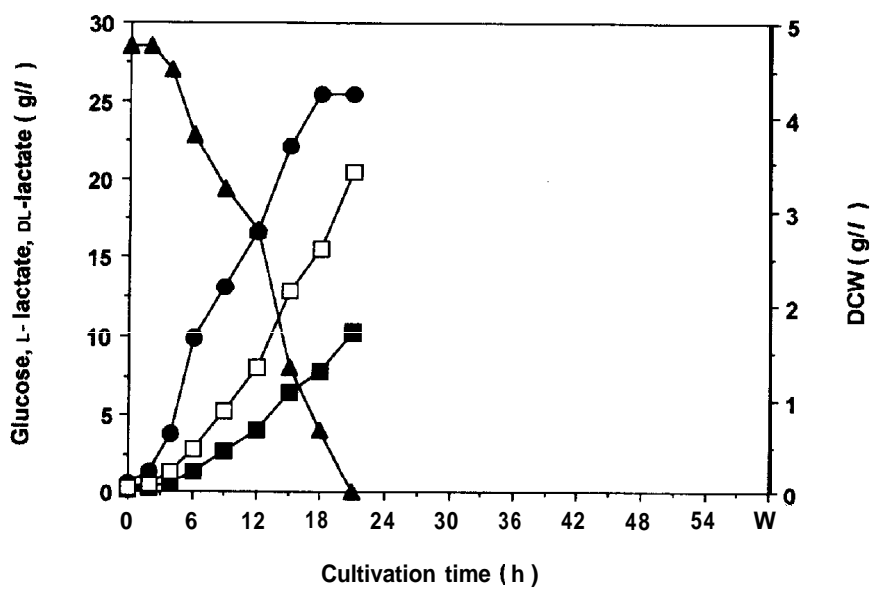

Fig. 6. Time course for jar culture of Pediococcus sp. ISK-1 grown in CMG with $5.0 \%$ mieki.

Symbols are the same as in Fig. 1.

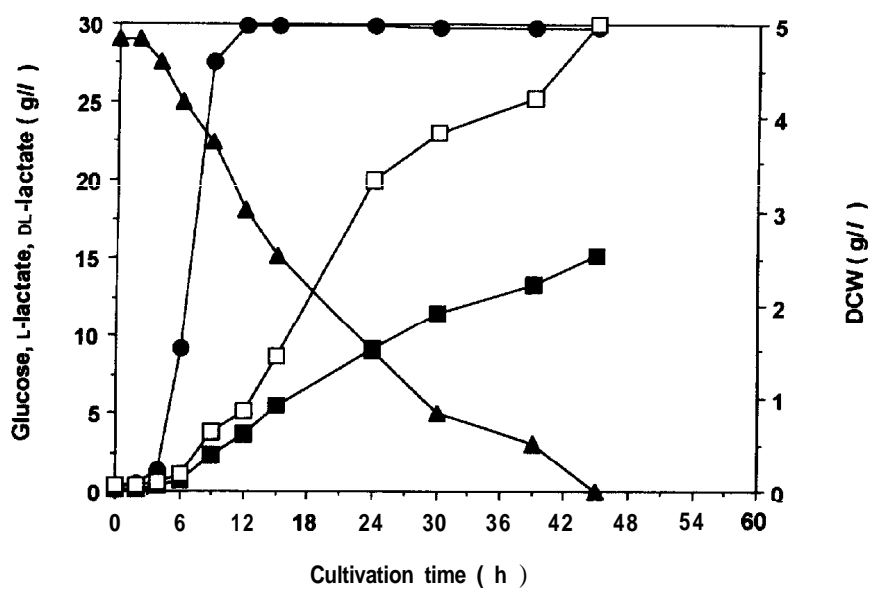

Fig. 7. Time course for jar culture of Pediococcus sp. ISK-1 grown in CMG with $10 \mathrm{ppm}$ mevalonic acid.

Symbols are the same as in Fig. 1 . 


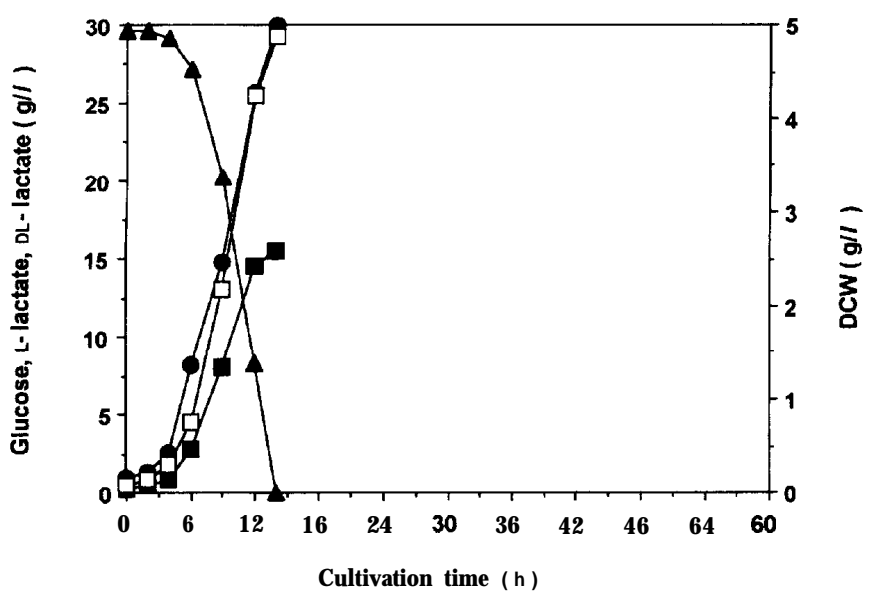

Fig. 8. Time course for jar culture of Pediococcus sp. ISK-1 grown in CMG with $\mathbf{5 . 0 \%}$ mieki and 10ppm mevalonic acid. Symbols are the same as in Fig. 1.

fermentation time improved from $60 \mathrm{~h}$ to $21 \mathrm{~h}$, with a maximum DCW of 4.24 , L-lactate at $10.3 \mathrm{~g} / \mathrm{l}$ and DL-lactate at $20.50 \mathrm{~g} / \mathrm{l}$. To confirm the effect of mevalonic acid, CMG with 10 ppm mevalonic acid was then tested. Figure 7 shows that mevalonic acid promoted growth and lactic acid production to yield a maximum DCW of 4.99, L-lactic acid at 15.15 $\mathrm{g} / l$ and DL-lactic acid at $29.94 \mathrm{~g} / l$, respectively, although consumption of glucose was prolonged until $45 \mathrm{~h}$ after the start of culture. The results indicated that mieki stimulated glucose consumption while mevalonic acid had an effect on the growth and lactic acid production. Thus, we examined with both mieki and mevalonic acid. Data for the culture with CMG plus 5.0\% mieki and 10 ppm mevalonic acid (Fig.8) showed that the lactate concentration was almost the same as that observed with CMG and mevalonic acid only. However, the culture with $\mathrm{CMG}$ and mieki plus mevalonic ascid reduced the fermentation time markedly.

\section{DISCUSSION}

The effects on cells of changes in the medium are quite difficult to quantify because of various cellular functions affect the transport of ions, atoms, and molecules that enter and leave the cell. We examined directly the effects generation time, and fermentation kinetics of strain ISK-1 in jar culture of CMG plus 5.0\% mieki, CMG plus $10 \mathrm{ppm}$ mevalonic acid and CMG plus 5.0\% mieki and 10 ppm mevalonic acid.

Figures 9, 10 and 11 illustrate the changes in fermentation kinetics of Pediococcus sp. ISK-1. Using the three media we observed various growth phases, as seen from the growth curves. The concentration of cells at which a transition takes place from one growth to another depends on both the characteristics of the cells and the composition of 


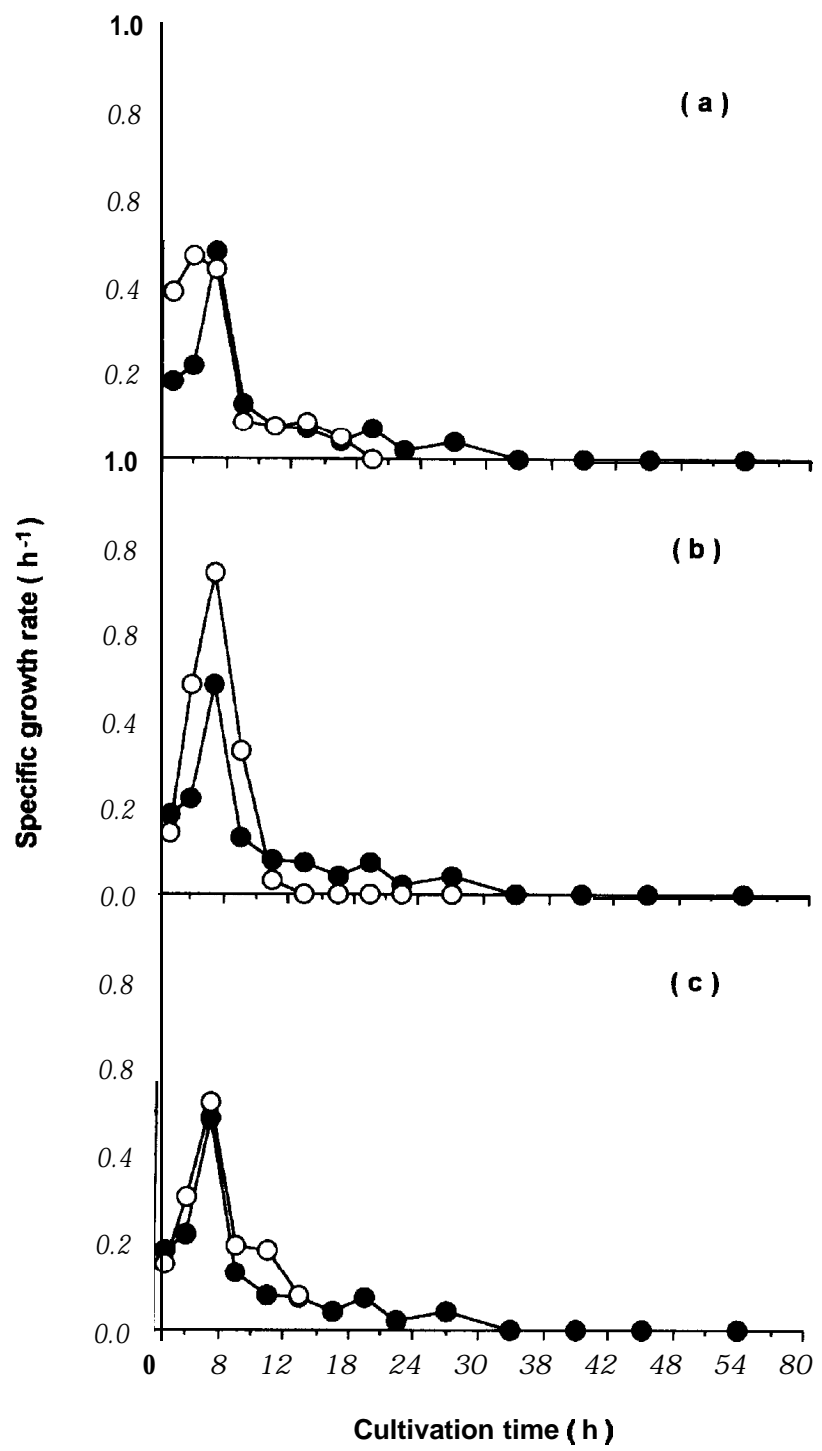

Fig. 9. Changes in the specific growth rate of Pediococcus sp. ISK-1 in CMG with $5.0 \%$ mieki (a), $10 \mathrm{ppm}$ mevalonic acid (b), and 5.0\% mieki and $10 \mathrm{ppm}$ mevalonic acid (c).

Closed symbols indicate the data for the control culture (CMG). Open symbols indicate the date 'for CMG with $5.0 \%$ mieki (a), $10 \mathrm{ppm}$ mevalonic acid (b), and 5.0\% mieki and $10 \mathrm{ppm}$ mevalonic (c). 


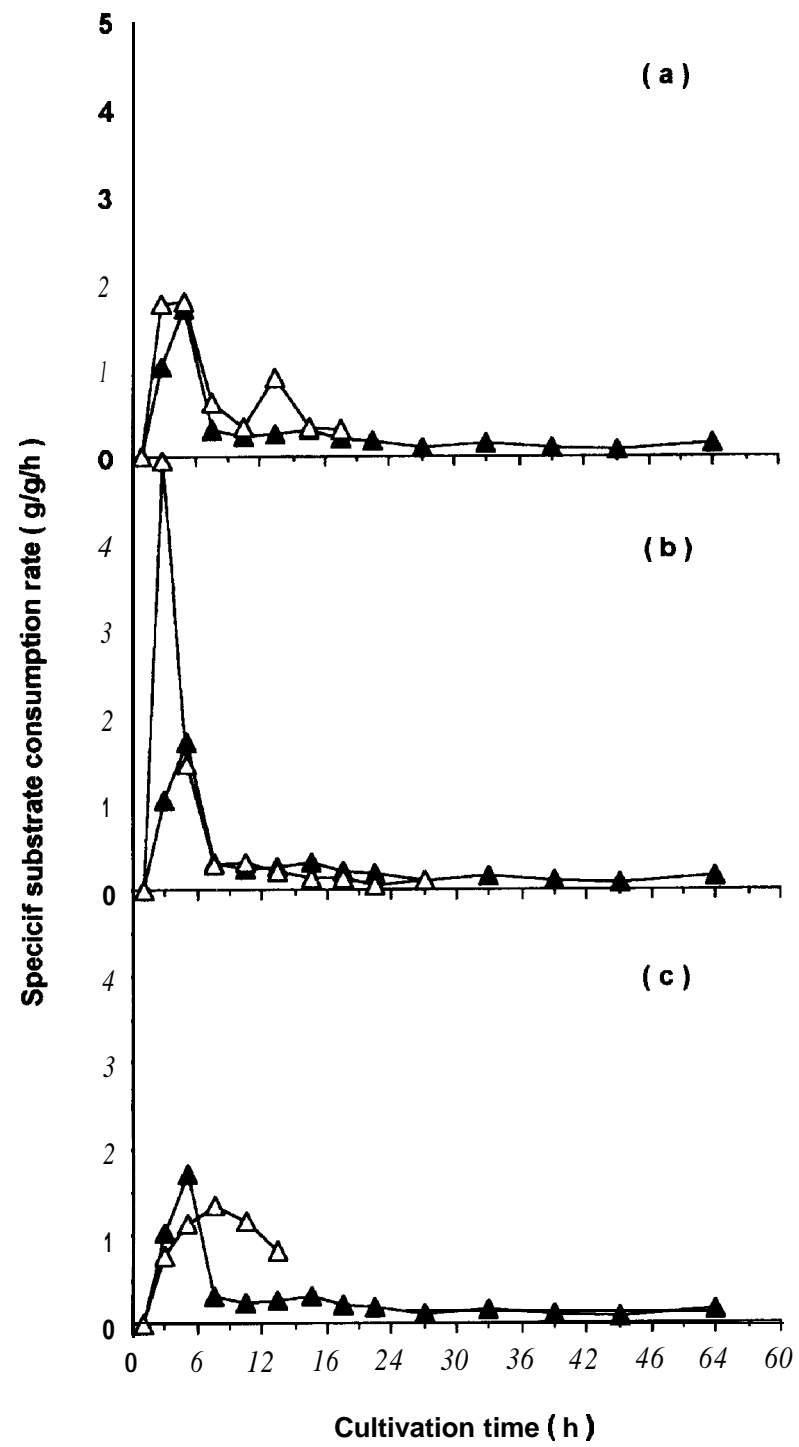

Fig. 10. Changes in the specific glucose consumption rate of Pediococcus sp. ISK-1 in CMG with 5.0\% mieki (a), $10 \mathrm{ppm}$ mevalonic acid (b), and $5.0 \%$ mieki and $10 \mathrm{ppm}$ mevalonic acid (c).

Symbols are the same as in Fig. 9. 


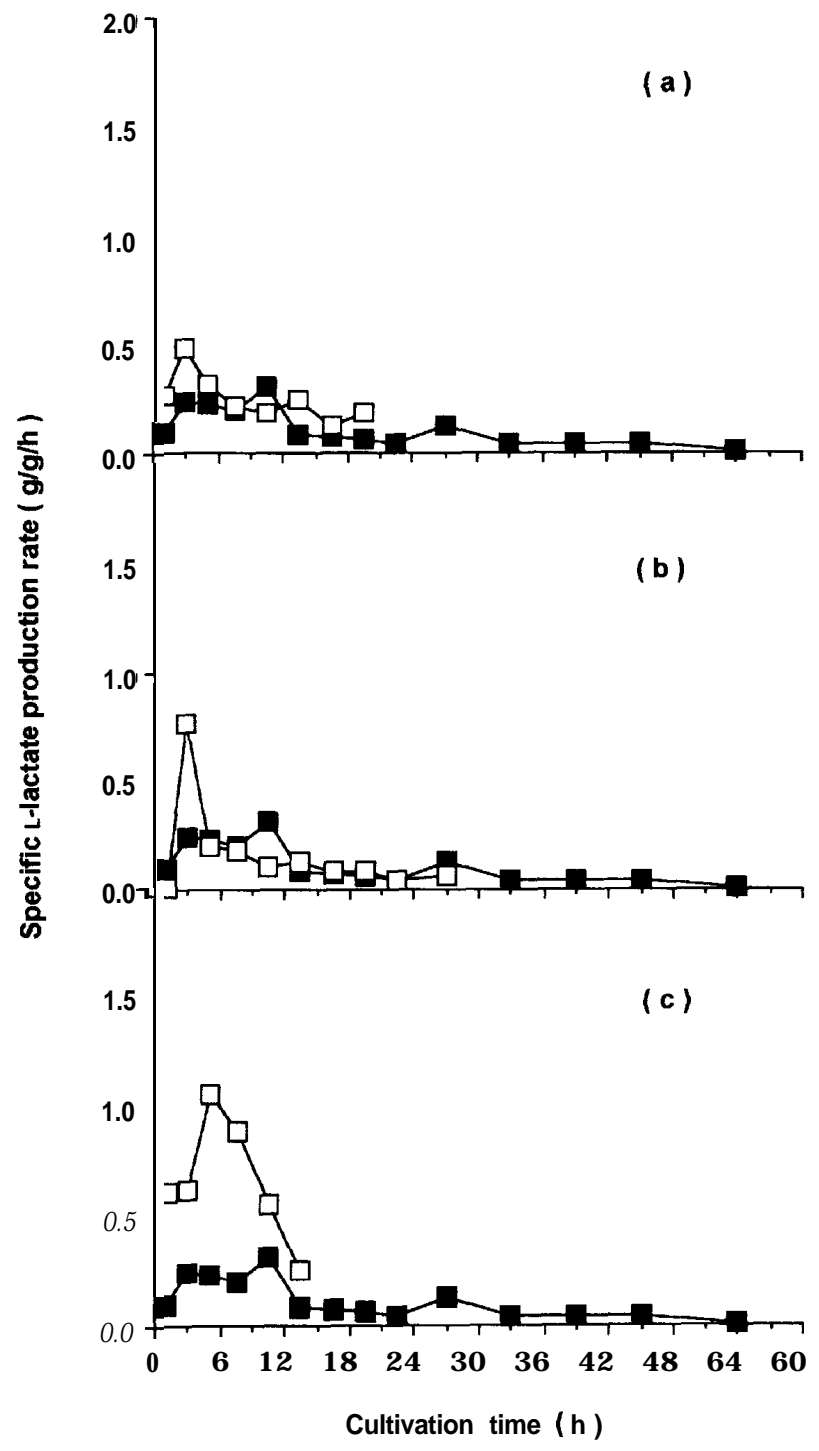

Fig. 11. Changes in the specific L-lactate production rate of Pediococcus sp ISK-1 in CMG with 5.0\% mieki (a), 10 ppm mevalonic acid (b), and $5.0 \%$ mieki and $10 \mathrm{ppm}$ mevalonic acid (c).

Symbols are the same as in Fig. 9. 
the culture medium. Consequently, the relative durations of the growth phases vary with specific rates of growth, substrate consumption and product formation. In CMG, the maximum specific rates of growth and glucose consumption were observed after a $5 \mathrm{~h}$ incubation. The specific substrate consumption rate was enhanced during the first $6 \mathrm{~h}$ of incubation by addition of 5.0\% mieki and by addition of $10 \mathrm{ppm}$ mevalonic acid (Fig.1Oa and $10 \mathrm{~b}$ ). However, the growth rate of strain ISK-1 was almost the same upon addition to CMG of 5.0\% mieki and $10 \mathrm{ppm}$ mevalonic acid (Fig. 9a and 9b). Figure 11 shows that the specific product formation rate enhanced during a $12 \mathrm{~h}$ incubation by addition of $5.0 \%$ mieki and $10 \mathrm{ppm}$ mevalonic acid. Addition of 5.0\% mieki and $10 \mathrm{ppm}$ mevalonic acid enhanced the specific substrate consumption rate and the product formation rate after 9 $\mathrm{h}$ of incubation (Fig. 10c and llc), while the specific growth rate was unchanged (Fig. 9c). These results indicate that in cultures of Pediococcus sp. ISK-1 in CMG that contained $30 \mathrm{~g} / \mathrm{l}$ glucose initially, 5.0\% mieki and $10 \mathrm{ppm}$ mevalonic acid markedly affected substrate utilization and product formation but this effect was not associated with growth. It is possible that two different effects of mevalonic acid were involved: mevalonic acid may have done as an activate to peptidoglycan transpeptidase to the degradation of amino acids in the cell walls; and it might have done as stimulator in the biosynthesis of vitamins A, D, E, and K (Ishimoto et al., 1971). Mieki might act as a nitrogen source and mevalonic acid might act as a growth factor and function as a vitamin so that together they might have a synergistic effect, acting together to promote the growth of this strain and lactic acid production. The medium developed in this study should help us to study the metabolism of mevalonic acid in Pediococcus sp. ISK-1.

\section{REFERENCES}

Amy, L. T. and D. G. Hoover 1988 Fermentation products from carbohydrate metabolism in Pediococcus pentosaceus PC39.J. Food. Prot., 51: 804-806

Blickstad, E. and M. Goran 1981 Growth and lactic acid production of Pediocorcus pentosaceus at different gas, environments, temperatures, $\mathrm{pH}$ values and nitrite concentrations. Eur.J.Appl. Microbiol.Biotechnol., 13: 170-174

Bowman, L. and E. Geiger 1984 Optimization of fermentation condition for alcoholic production. Biotechnol, Bioeng., 26: 1492-1497

Chen,S.L. 1981 Optimization of batch alcoholic fermentation of glucose syrup substrate. Biotechnol. Bioeng., 23: 1827-1836

Cheynier, V., M. Feinberg, C. Chararas and C. Ducanze 1983 Application of response surface methodology to evaluation of bioconversion experimental condition. Appl. Environ. Microbiol., 45: 634-639

Houng, J. J., K. C. Chen and W. H. Hsu 1989 Optimization. of cultivation medium composition for isoamylase production. Appl. Microbiol. Biotechnol., 31: 61-64

Ishimoto, M., S. Minakami, S. Mizushima, T. Oshima and H. Wada 1971 In " Metabolic Maps", 3rd Ed, Kyoritsu Publishing Company, Tokyo, Japan, pp. 12, 19

Kitahara, K., T. Kaneko, and 0. Goto 1957 Taxonomic studies on the hiochi-bacteria, specific saprophytes of sake. I. Isolation and grouping of bacterian strains. J.Gen.Appl.Microbiol., 3: 102-110

Kitahara, K., T. Kaneko, and 0. Goto 1957 Taxonomic studies on the hiochi-bacteria, specific saprophytes of sake. II. Identification and clasification of hiochi-bacteria. J. Gen. Appl.Microbiol., 3: 111-120

Oiki, H., K. Sonomoto and A. Ishizaki 1996 Stimulation by Natural Rubber Serum Powder of the Growth of Bifidobacteriumbifidum.J. Fuc. Agr., KyushuUniv, 40: 271-277

Silveira, R. G., T. Kakizono., S. Takemoto., N. Nishio and S. Nagai 1991 Medium optimization by an orthogonal array design for the growth of Methanosarchina barkeri.J.Ferment. Bioeng., 72: 20- 
25

Sneath, P. H. A., N. S. Mair., M. E. Sharpe and J. G. Holt 1986 In “ Bergey's manual of systematic bacteriology", Vol. 2, Williams and Wilkins, Baltimore, pp. 1228-1229

Uchimura, T. and S. Okada 1992 In "Nyusankin jikken manual", Asakura Shoten, Tokyo, pp 111 (in Japanese)

Zertuche, L. and R. R. Zall 1985 Optimizing alcohol production from whey using computer technology. Biotechnob Bioeng., 2'7: 547-555 